\title{
DESCRIPTION OF LARVA OF SEJUS HINANGENSIS (ACARI: MESOSTIGMATA: SEJIDAE) FROM THE FAR EAST OF RUSSIA
}

\author{
Vyacheslav A. Trach ${ }^{1 *}$ and Andrei V. Tolstikov ${ }^{2}$ \\ ${ }^{1}$ I. I. Mechnikov Odessa National University, Odessa, Ukraine \\ ${ }^{2}$ Tyumen State University, Tyumen, Russia \\ *corresponding author; e-mail: vatrach@gmail.com
}

\begin{abstract}
The mesostigmatic mite Sejus hinangensis Hirschmann and Kaczmarek, 1991 is recorded for the first time in the Far
\end{abstract} East of Russia. The first description of the larva of S. hinangensis and a key to larvae of the genus Sejus are provided.

KEY WORDS: Parasitiformes, Sejus, new record, larval morphology, key.

DOI: 10.21684/0132-8077-2016-24-2-175-179

\section{INTRODUCTION}

The family Sejidae Berlese, 1885 includes 47 mite species from five genera: Sejus Koch, 1836 (26 species), Epicroseius Berlese, 1905 (17 species), Africasejus Lekveishvili and Klompen, 2006 (two species), monotypic Zuluacarus Trägårdh, 1906 and Adenosejus Lekveishvili and Krantz, 2004 (Hirschmann et al. 1991; Fain and Galloway 1994; Hirschmann and Wiśniewski 1994; Lekveishvili and Klompen 2004, 2006; Lekveishvili and Krantz 2004; Kaczmarek 2008). The family is distributed in the warm temperate and tropical regions of the world, with its constituent species often associated with wood. The second nymphal instar, the deutonymph, may be dimorphic, with one "normal" (homeomorphic) morph and a heteromorphic morph specialized for phoresy, often on cerambycid beetles (Lekveishvili and Klompen 2006).

Mites of the genus Sejus are known from the Afrotropical (S. camerunis Hirschmann and Wiśniewski, 1994; S. mesoafricanus Hirschmann and Wiśniewski, 1994), the Australasian (S. australis Hirschmann and Kaczmarek, 1991; S. novaezealandiae Fain and Galloway, 1994), the Nearctic ( $S$. americanus (Banks, 1902); S. carolinensis Lekveishvili and Klompen, 2004; possibly $S$. bakeriarmatus Hirschmann, 1991), the Neotropical (S. armatus (Fox, 1947); S. boliviensis Hirschmann and Kaczmarek, 1991; S. cubanus Wiśniewski and Hirschmann, 1991; S. geometricus Hirschmann and Kaczmarek, 1991; S. insulanus Trägårdh, 1931; S. paricornis Berlese, 1916; S. venezuelanus Hirschmann and Wiśniewski, 1994), and the Palaearctic regions (S. acanthurus Canestrini, 1884; $S$. baloghi (Athias-Henriot, 1960); S. bicaudus Berlese; S. bugrovskii Wisniewski and Hirschmann, 1991; S. hinangensis Hirschmann and Kaczmarek, 1991; $S$. italicus Berlese, 1916; S. polonicus Hirschmann and Kaczmarek, 1991; S. posnaniensis Hirschmann and
Kaczmarek, 1991; S. rafalskii Wisniewski and Hirschmann, 1991; S. sejiformis (Balogh, 1938); S. stebaevi Wisniewski and Hirschmann, 1991; S. togatus Koch, 1836)(Athias-Henriot 1960; Hirschmann et al. 1991; Fain and Galloway 1994; Hirschmann and Wiśniewski 1994; Lekveishvili and Klompen 2004; Kaczmarek 2008; Walter 2013). Only five species have been reported from Asia: (S. bugrovskii; S. hinangensis; S. sejiformis; S. stebaevi; S. togatus) (Bregetova 1977; Hirschmann et al. 1991).

The correct identification of most groups of mesostigmatic mites based only on larval stage is impossible, and keys to larvae of these groups are absent. Mites of the family Sejidae are an exception (Hirschmann 1991). Currently, the larval stage is described in six species of the genus Sejus: S. australis, S. baloghi, S. boliviensis, S. carolinensis, S. posnaniensis, and S. togatus (AthiasHenriot 1960; Hirschmann et al. 1991; Lekveishvili and Klompen 2004).

During a study of mites associated with bark beetles in Russia, immature mites of the genus Sejus were recorded under the bark of the Manchurian fir (Abies nephrolepis) in the galleries of the bark beetle Polygraphus proximus Blandford, 1894 (Coleoptera: Curculionidae: Scolytinae). Deutonymph and protonymph were identified as Sejus hinangensis. Type series of $S$. hinangensis included specimens from Germany, Poland, and Russia (Republic of Tyva). Later this species has been regularly recording from Poland (references in Gwiazdowicz 2010). Mites of this species occur in woods and under the bark of various trees (spruce, pine, fir, oak), S. hinangensis is also recorded from the galleries of Ips typographus under the bark of fir (Hirschmann et al. 1991).

The aim of this paper is to provide the first description of larva of $S$. hinangensis and a key to all known larvae of the genus Sejus. 


\section{MATERIAL AND METHODS}

Branches and twigs of the Manchurian fir, $A b$ ies nephrolepis, containing galleries of the bark beetle, Polygraphus proximus Blandford, 1894, were taken from a coniferous forest in the Russian Far East. The samples were placed into plastic boxes and kept at room temperature in laboratory. Galleries of $P$. proximus were examined with a stereomicroscope Discovery V8, Carl Zeiss. The mites were mounted in Hoyer's medium for the light-microscopy. The morphology of mites was studied using the Carl Zeiss Axio Imager A2 compound microscope with DIC and phase contrast objectives. The morphological terminology generally follows that of Evans and Till (1979). Dorsal setae were labelled according to the system of Lindquist and Evans (1965). All pore-like structures, glandular openings (solenostomes) and poroids (lyrifissures) have been named as pores. The length of the second cheliceral segment was measured from the base to the apex of the fixed digit. Leg length was taken from the base of the coxa to the apex of the tarsus, excluding the ambulacrum. Measurements are given in micrometres $(\mu \mathrm{m})$. The studied material is deposited in the collection of the Department of Zoology of I. I. Mechnikov Odessa National University (Odessa, Ukraine) and in the mite collection of the Tyumen State University Museum of Zoology (Tyumen, Russia).

\section{SYSTEMATICS}

\section{Family Sejidae}

Genus Sejus Koch, 1836

Type species: Sejus togatus Koch, 1836, by monotypy

\section{SEJUS HINANGENSIS HIRSCHMANN AND KACZMAREK, 1991}

Figs 1-2

Larva. Dorsum (Fig. 1A). Idiosoma oval; 462-479 long (with pygidial projections) and 273-294 maximum width. Podonotal shield ovoid; 214-218 long and 168-172 maximum width; smooth; with longitudinal lines in the middle; with nine pairs of serrated setae $(j 1, j 3-j 6, z 2, z 4, z 5, s 4)$ and two pairs of distinguishable pores. Pygidial shield punctate; with four pairs of long setae inserted on posterior projections $(J 5, Z 4, Z 5, S 5 ; S 5$ and $Z 5$ visible ventrally); glands $g Z 4$ and pair of processes with sucker-like apex (46-48 long). Soft cuticle smooth; with five pairs of weakly serrated setae (J2, J3, Z3, s6, S4; S4 visible ventrally) and one pair of distinguishable pores. Almost all of dorsal setae slightly lanceolate distally. Measurements of setae: $j 132-34, j 325-27, j 423-27, j 5$ 29-32,j6 59-63, z2 27-29, z4 27-32, z5 82-90, s4 63-71, s6 34-38, J2 23-25, J3 29-34, J5 265-273, Z3 36-38, Z4 185-197, Z5 65-67, S4 25-27, S5 193-206.

Venter (Fig. 1B). Tritosternum with elongate base; laciniae pilose apically; base of tritosternum length 21, laciniae length 55-57. Sternal shield smooth; 118-120 long and 78-82 wide at narrowest level between coxae II and III; bearing three pairs of simple setae (st1-st3). Unsclerotized cuticle around of anus with two pairs of simple setae $(J V 1, J V 5)$, simple paraanal setae ( $p a)$, weakly serrated postanal seta $(p o)$ and three pairs of distinguishable pores. Measurements of setae: st 1 21-25, st2 21-25, st3 21-25, JV1 21-23, JV5 23-25, pa 27-29, po 132-134.

Gnathosoma. Second cheliceral segment 97-99 long; fixed cheliceral digit with a row from about ten teeth and subdivided apical tooth, pilus dentilis setiform; movable cheliceral digit with two parallel rows of small teeth (Fig. 1C). Gnathotectum triangular; with serrated anterior margin (Fig. 1D). Palp 153-160 long; number of setae (trochanter to tarsus): 0-4-5-12-11; apotele 2-tined; seta $d 1$ of femur slightly lanceolate distally, other setae of femur and genu weakly serrated, setae of tibia and tarsus smooth; femur with two rows of small denticles dorsally; anterodistal corner of genu with two enlarged denticles (Figs. 1E-G). Subcapitulum 111-116 wide at widest level; with long row of small denticles at base (Fig. 1H). Deutosternum with 12 transverse rows of deutosternal denticles (1-6 denticles per row). Corniculus horn-like. Internal malae projecting beyond tips of corniculi; labrum projecting somewhat beyond tips of internal malae. Setae $h p 1$ thickened and blunted, setae $h p 2$ simple. Measurements of setae: $h p 16, h p 2$ 29-34.

Legs (Fig. 2A-D). Lengths: I 378-386, II 302-315, III 315-323. Leg chaetotaxy normal for Sejidae. Chaetotaxy: leg I: coxa 2, trochanter 4 (1 $0 / 0$ 0/2 1), femur 10 (2 2/1 2/1 2), genu 8 (1 2/1 2/1 1), tibia 8 (1 2/1 2/1 1); leg II: coxa 2 , trochanter 4 (1 0/0 0/2 1), femur $7(12 / 12 / 01)$, genu $6(12 / 0$ $2 / 01)$, tibia $7(11 / 12 / 11)$, tarsus 16 (3 3/2 3/2 3); leg III: coxa 2 , trochanter $4(11 / 00 / 20)$, femur 5 (1 2/1 1/0 0), genu $6(12 / 02 / 01)$, tibia $7(1 / 1 / 12 / 1$ $1)$, tarsus $16(33 / 23 / 23)$. Most of setae weakly serrated, largest of them lanceolate distally; setae $a l 1, a l 2, a v 1, a v 2, p v 1, p v 2, p l 1, p l 2$ on tarsi II and 


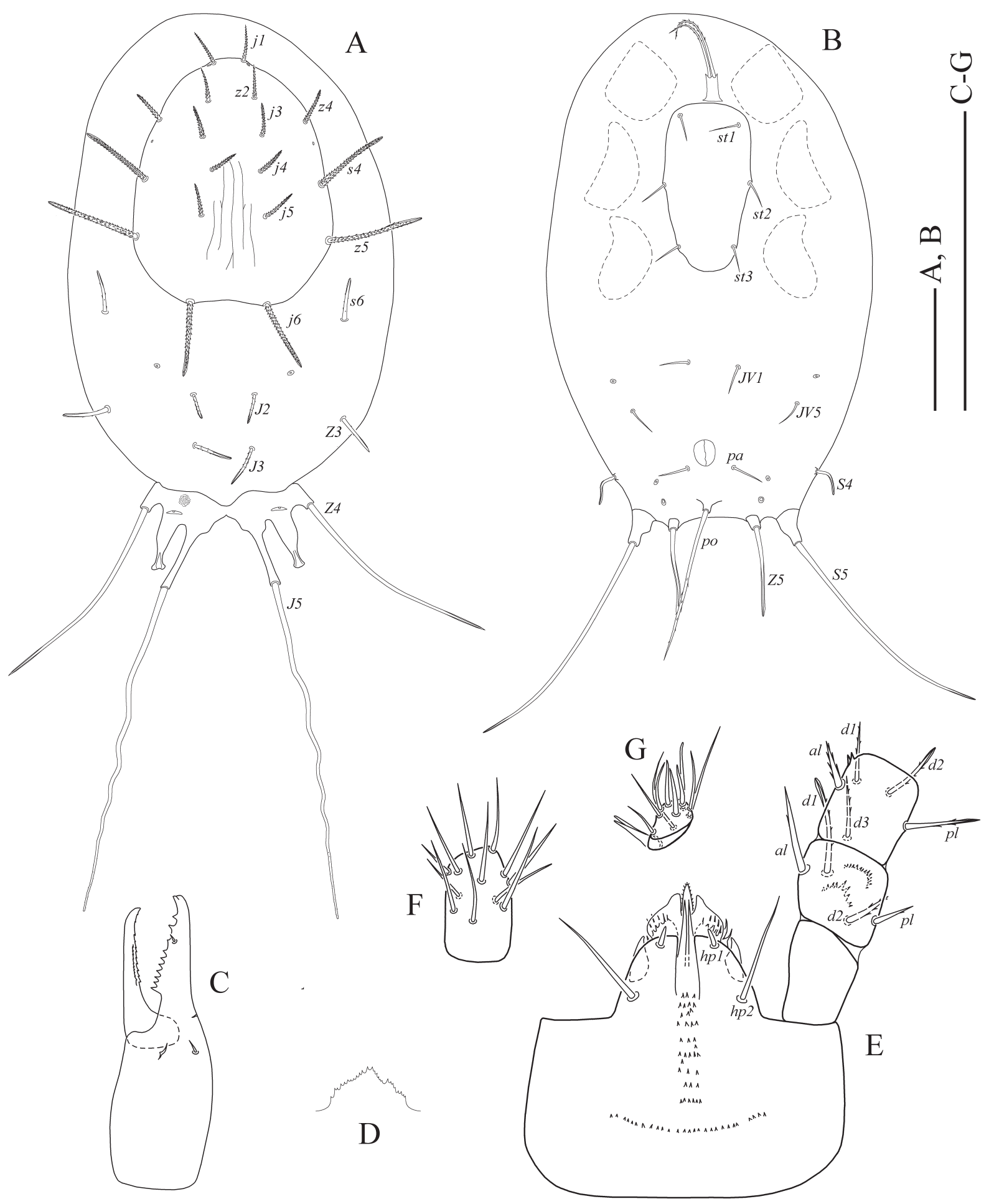

Fig. 1. Sejus hinangensis Hirschmann and Kaczmarek, 1991, larva: A—idiosoma, dorsal view; B-idiosoma, ventral view; C-chelicera; D - gnathotectum; E - subcapitulum and palp (from trochanter to genu), ventral view; F-palptibia, dorsal view; G-palptarsus, dorsal view. Scale bar $100 \mu \mathrm{m}$.

III 3-tined. Tarsus I with acrotarsus; claws I-III well developed; ambulacral stalk of legs II-III with acuminate ventro-lateral processes.

Material examined. Three deutonymphs, one protonymph, two larvae: Russia, Primorsky Kray, Lazo reg., 4330'04.6' N, 133³4'47.1' 'E, 902 masl, 28 August 2016, in galleries of the bark beetle Polygraphus proximus Blandford, 1894 under the bark of Manchurian fir (Abies nephrolepis), colls. A. A. Khaustov, M. Yu. Mandelshtam, V. A. Trach.

Remarks. Hirschmann et al. (1991) erected in the genus Sejus species-group "togatus" (with spe- 
V. A. Trach and A. V. Tolstikov

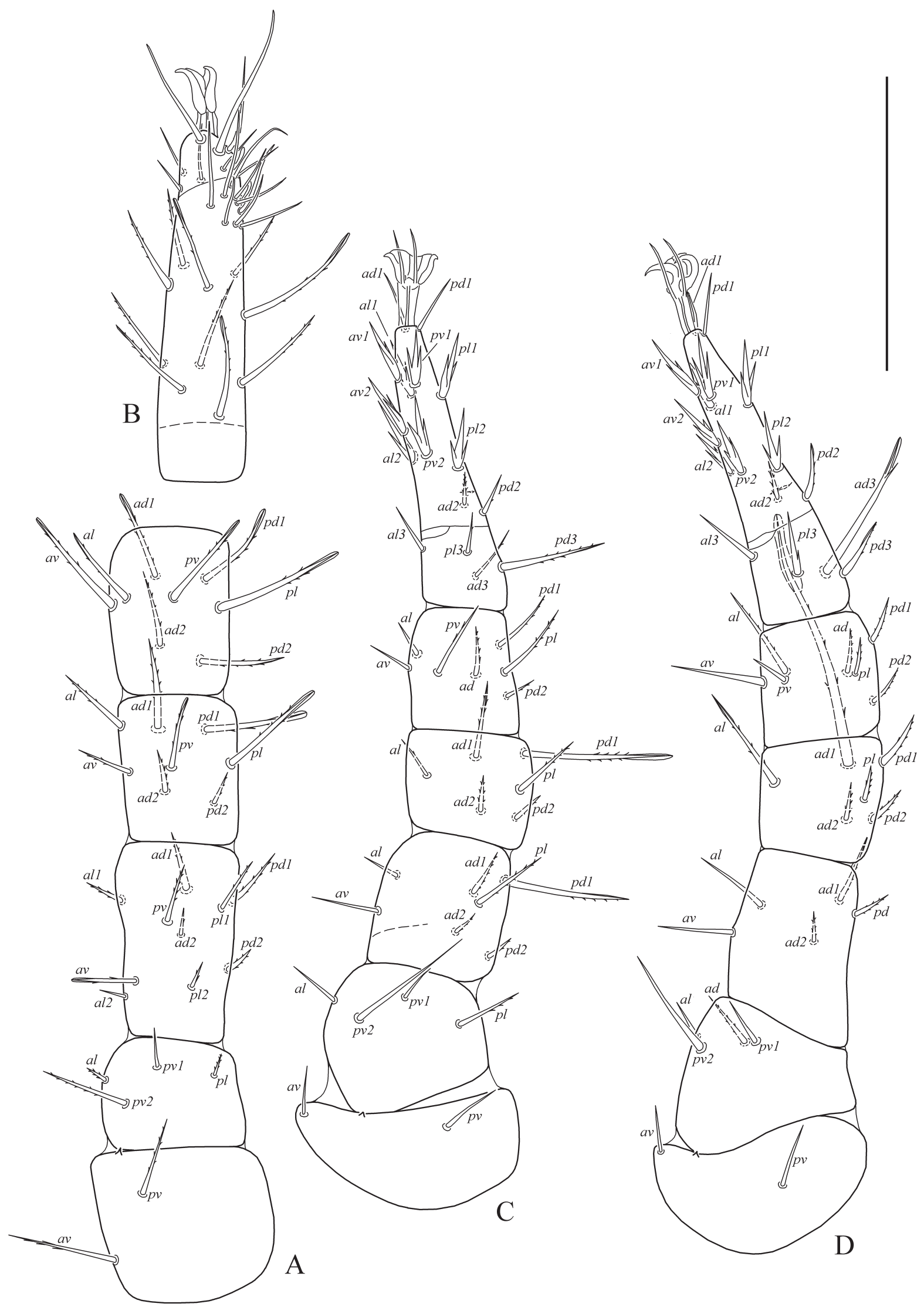

Fig. 2. Sejus hinangensis Hirschmann and Kaczmarek, 1991, larva: A-leg I (from coxa to tibia), ventral view; Btarsus I, dorsal view; C—-leg II, ventral view; D—leg III, ventral view. Scale bar $100 \mu \mathrm{m}$. 
cies $S$. hinangensis, S. polonicus, and S. togatus) based on the morphology of adult females, males and nymphs. Their morphological similarity was also confirmed by Lekveishvili and Klompen (2006). The presence of long sucker-like processes on the pygidial shield in the larva of $S$. hinangensis indicates its affinity to $S$. togatus.

\section{A key to larvae of the genus Sejus}

1. Setae $j 6$ extending to pygidial shield S. posnaniensis

— Setae $j 6$ not extending to pygidial shield ..... 2 2. Setae $j 1$ located on unsclerotised cuticle S. boliviensis

- Setae $j 1$ located on podonotal shield .. 3

3. Pygidial shield with a pair of long caudal processes with sucker-like apex .. 4

- Pygidial shield without long caudal processes with sucker-like apex

4. Setae Z4, Z5, S4, S5 pointed and lanceolate distally S. hinangensis

— Setae Z4, Z5, S4, S5 with capitate tips S. togatus

5. Anal shield well developed S. australis

- Anal shield absent .. 6

6. Setae $S 4$ pointed; sternal setae subequal S. baloghi

- Setae $S 4$ with capitate tips; setae st1 significantly longer than $s t 2$ and $s t 3$...... S. carolinensis

\section{ACKNOWLEDGEMENTS}

The authors thank Dr. Alexander Khaustov (Tyumen State University, Tyumen, Russia) for the help with collecting material and reviewing the manuscript. Many thanks are due to Dr. Mikhail Mandelshtam (Genome Research, Saint-Petersburg S. M. Kirov State Forest Technical University, Saint-Petersburg, Russia) for the help in collecting material and identification of the bark beetle. The present research was supported by the grant from the Russian Science Foundation, project No. 1614-10109, to Dr. A. A. Khaustov.

\section{REFERENCES}

Athias-Henriot, C. 1960. Contribution aux mésostigmates d'Algérie (Parasitiformes: Liroaspidae, Veigaiidae). Acarologia, 2: 159-174.

Bregetova, N. G. 1977. [Cohort Sejina] In: M. S. Gilyarov and N. G. Bregetova (Eds.). A Key to the Soil-Inhabiting Mites of the Mesostigmata. Nauka, Leningrad, p. 25-26. [In Russian]
Evans, G. O. and Till, W. M. 1979. Mesostigmatic mites of Britain and Ireland (Chelicerata: Acari-Parasitiformes). An introduction to their external morphology and classification. Transactions of the Zoological Society of London, 35: 139-270.

Fain, A. and Galloway, T. D. 1993. Mites (Acari) from nests of sea birds in New Zealand II. Mesostigmata and Astigmata. Bulletin de l'Institut royal des sciences naturelles de Belgique, Entomologie, 63: 95-111.

Gwiazdowicz, D. J. 2010. Sejoidea, Antennophoroidea, Celaenopsoidea, Microgynioidea (Acari, Mesostigmata) of Poland. Bogucki Wydawnictwo Naukowe, Poznan. 142 pp.

Hirschmann, W. 1991. Gangsystematik der Parasitiformes. Teil 529. Weltweite Revision der Ganggattung Sejus C. L. Koch 1836 (Trichopygidiina)Gangmerkmale-Stadienmerkmale-Bestimmungtabellen. Acarologie, 38: 107-135.

Hirschmann, W. and Wiśniewski, J. 1994. Sejus venezuelanus nov. spec. (Trichopygidiina) aus Venezuela. Acarologia, 35: 21-26.

Hirschmann. W., Wiśniewski J., and Kaczmarek, S. 1991. Gangsystematik der Parasitiformes. Teil 530. Weltweite Revision der Ganggattung Sejus C. L. Koch 1836 (Trichopygidiina). Neubeschreibung von 26 Sejus-Arten. Wiederbeschreibung der Typenart. Acarologie, 38: 136-214.

Kaczmarek, S. 2008. Epicrosejus blaszaki sp. nov. (Acari: Mesostigmata: Sejidae). A new mite species from Korean Peninsula. Annales Zoologici, 58: 261-265.

Lekveishvili, M. and Klompen, H. 2004. A new species of Sejidae (Acari: Mesostigmata) from the Southeastern U.S.A. International Journal of Acarology, 30: 229-238.

Lekveishvili, M. and Klompen, H. 2006. New classification of the family Sejidae (Acari: Mesostigmata) based on morphological analysis. Journal of Natural History, 40: 2317-2339.

Lekveishvili, M. and Krantz, G. 2004. A new genus of the family Sejidae (Acari: Mesostigmata) based on Sejus krantzi and S. manualkrantzi Hirschmann, 1991. Systematic and Applied Acarology, Special Publications, 20: 1-4.

Lindquist, E. E. and Evans, G. O. 1965. Taxonomic concepts in the Ascidae, with a modified setal nomenclature for the idiosoma of the Gamasina (Acarina: Mesostigmata). Memoirs of the Entomological Society of Canada, 47: 1-64.

Walter, D. E. 2013. A new genus and family of sejine mites (Acari, Parasitiformes, Mesostigmata, Sejoidea) based on new species from Lord Howe Island and Brazil, and a redescription of Sejus americanus (Banks, 1902). Zootaxa, 3691 (3): 301-323. 